\title{
O POTENCIAL DA SEMANA DO MEIO AMBIENTE PARA O DEBATE E SENSIBILIZAÇÕES DE PRÁTICAS AMBIENTAIS SUSTENTÁVEIS
}

\section{The potential of the environmental week for the debate and awareness of sustainable environmental practices}

\author{
Danieli Barbosa de Araujo \\ Universidade Estadual de Londrina \\ danieli_g5@hotmail.com \\ Larissa Alves de Oliveir \\ Universidade Estadual de Londrina \\ larissa-alvez@hotmail.com
}

\begin{abstract}
Artigo enviado para publicação em 27/04/2020 e aceito em 11/10/2020
\end{abstract}
DOI: $10.12957 /$ tamoios.2020.50499

\begin{abstract}
Resumo
Qual o papel dos sujeitos no enfrentamento dos problemas ambientais vigentes? Qual a relação dos sujeitos com o meio em que vivem e o modo como cuidam desses ambientes? Tais indagações ressaltam o compromisso ambiental que deve ser inerente a todos, e por vezes, estimulam práticas capazes de minimizar impactos ambientais. A Semana do Meio Ambiente, frequentemente realizada nas instituições de educação básica, promovem espaços para tais reflexões, assim como estimulam atividades e ações de grande relevância ambiental. O presente ensaio visa propor uma reflexão acerca da importância da Semana do Meio Ambiente na promoção de momentos de discussão e reflexão acerca da crise ambiental, e do compromisso individual e coletivo na reversão de atitudes que degradem o meio ambiente. As escolas apresentam-se como um ambiente frutífero para a incorporação de ações que visem o trabalho coletivo e o cuidado com o meio no qual se vive. Fazendo uso da metodologia de observação e participação, foi possível através do exemplo do Colégio Estadual Manuel Bandeira em Cambé, Paraná/PR, perceber como oficinas e debates acerca da questão ambiental desencadeia ações mais sustentáveis, promovendo o cuidado com o ambiente escolar e com o mundo.
\end{abstract}

Palavras-Chave: Semana do meio ambiente; Déficit de natureza; Sustentabilidade; Práticas ambientais; Educação básica.

\begin{abstract}
What is the role of individuals in facing current environmental problems? What is the relationship of the individuals with the environment they live in and the way they care for these environments? Such inquiries underscore the environmental commitment that must be inherent to everyone, and sometimes encourage practices capable of minimizing environmental impacts. The Environment Week, often held in basic education institutions, promotes spaces for such reflections, as well as stimulating activities and actions of great environmental relevance. This article proposes a reflection on the importance of the Environment Week to promote moments of discussion and reflection about the environmental crisis and the individual and collective commitment to reversing attitudes that degrade the environment. Schools present themselves as an effective environment for the incorporation of actions aimed at collective work and care for the environment in which they live. Using the methodology of observation and participation, it was possible, through the example of Colégio Manuel Bandeira (Manuel Bandeira High School) in Cambé, Paraná/PR, to understand how workshops and debates on the environmental issue trigger more sustainable actions, promoting good care of the school environment and the world.
\end{abstract}

Keywords: Environment Week; Nature's deficit; Sustainability; Environmental practices; Basic education. 


\section{Introdução}

A relação Homem-Terra encontra-se cada vez mais fragilizada. Há uma hostilidade e passividade em relação aos impactos ambientais, mesmo em meio a uma crescente preocupação com a vida do planeta. Todavia, pequenas práticas têm caminhado na contramão dessa negligência e mostrado que o compromisso ambiental pode e deve ser assumido por todos.

A Geografia, ao proporcionar um despertar da consciência geográfica, colocando o sujeito frente à realidade circundante, convida a uma reflexão sobre as atitudes humanas no mundo, sendo de fundamental importância nos debates acerca do compromisso ambiental. Trazendo em seu cerne a proposta da geograficidade, a qual expressa a própria essência geográfica de ser-e-estar-no-mundo (Dardel, 2011), a geografia escolar deve fazer florescer a relação orgânica entre Homem-Terra e ressaltar o compromisso global com o meio ambiente.

Enquanto caminho promissor para o debate das questões ambientais, o ensino de geografia ressalta a importância do entendimento do homem sobre o mundo que habita, compreendendo que sua interação faz parte de sua própria existencialidade. Dardel (2011, p. 89), menciona "é necessário, portanto, compreender a geografia não como um quadro fechado em que os homens se deixam observar [...] mas como o meio pelo qual o homem realiza sua existência [...]”. Desse modo, há no espaço da sala de aula a possibilidade de refletir sobre as inúmeras formas de conceber o mundo, tentando, por meio dos conteúdos geográficos, entendimentos das muitas realidades e o avanço das discussões sociais e científicas.

Neste sentido, o intuito do presente artigo é mostrar como a Semana do Meio Ambiente, celebrada mundialmente, pode ser um caminho para a visibilidade de boas práticas ambientais, surtindo efeitos duradouros e sensibilizando para ações mais sustentáveis.

O caminho metodológico deu-se a partir da pesquisa qualitativa, envolvendo duas frentes de trabalho: dados primários e dados secundários, ou seja, de campo e de gabinete. Os trabalhos de gabinete consistiram na seleção e análise de pesquisas em meio eletrônico, revisão bibliográfica, envolvendo a temática ambiental e a importância de metodologias que levem o educando a se envolver de forma corpórea e intelectual com a proposta apresentada. Complementarmente, realizou-se levantamentos de dados primários com o mesmo fim, em escala local, no Colégio Estadual Manuel Bandeira, localizado no município de Cambé, Paraná/PR. Como resultados, a partir de um viés participativo, demostra-se como é possível instrumentalizar uma práxis-pedagógica que valorize e esteja engajada na formação do cidadão crítico, participativo e ativo no processo educativo ambiental.

O presente artigo divide-se em duas partes. A primeira, intitulada "A problemática ambiental na sociedade do consumo", apresenta algumas problemáticas que permeiam os sujeitos com as questões ambientais, assim como propõem uma reflexão sobre como o modo de vida de parte da sociedade contemporânea leva a descompassos, não somente ambientais, mas também sociais.

$\mathrm{Na}$ segunda parte do trabalho, "Dia mundial do meio ambiente e seu potencial para o desenvolvimento de práticas ambientais sustentáveis" é apresentado uma prática realizada no colégio supracitado, como forma de ressaltar o trabalho que vem sendo feito por diversas instituições de ensino e de como esses momentos de debates e práticas, proporcionados pela Semana do Meio Ambiente, podem conduzir os sujeitos a novas condutas de cuidado com o mundo. 


\section{A problemática ambiental na sociedade do consumo}

Sabe-se que o processo produtivo atual é considerado um dos principais causadores da degradação do sistema ambiental, principalmente pelo modo como o uso dos recursos são utilizados - em uma proporção muito acima da sua capacidade de renovação. Junto a este processo atrela-se o consumismo desenfreado e inconsciente, gerando custos ambientais e sociais que mais do que nunca precisam ser repensados e minimizados.

Os modos de produção, neste sentido, revelam práticas insustentáveis que priorizam o lucro, não respeitando o tempo orgânico da natureza e comprometendo, seriamente, o meio no qual vivemos. Tal fato reafirma a falsa ideia de supremacia sobre a natureza, na qual o ser humano aparece como detentor e modificador dos espaços naturais e não como dependente dele.

Junto a isso somam-se ainda as experiências cotidianas contemporâneas, cada vez mais mediadas pela tecnologia, o que faz com que a corporeidade do sujeito se mantenha intimamente ligada com construções artificiais e técnicas em detrimento do espaço natural. Deste modo, remodelam-se algumas ações e comportamentos, colocando-nos, muitas vezes, como expectadores do meio ambiente e não como parte integrante do mesmo. Os saberes vernaculares (Claval, 2010), as experiências sensoriais com o espaço são cada vez menos privilegiadas. A falta de contato com o outro, com os espaços, com o meio ambiente em si, marcam uma profunda perda de sensibilidade e uma passividade de sentidos e ações.

As mudanças sociais subjetivas, iniciadas pelo juízo acerca dos indivíduos dentro da própria sociedade de consumo, "uma sociedade que julga e avalia seus membros principalmente por suas capacidades e sua conduta relacionadas ao consumo" (BAUMAN, 2007, p. 109), afasta os que pouco podem consumir e enaltecem os que integram o ciclo de consumismo. Para Santos (2007), o consumo inconsciente estimula uma das piores características do homem: o individualismo. O mesmo, mantido pelo consumismo, leva ao aniquilamento da personalidade sem a qual se corrói as singularidades e não se reconhece o humano "como distinto, a partir da igualdade entre todos" (SANTOS, 2007, p. 49).

O individualismo leva o homem à alienação ao passo que ele se torna ímpar na sociedade massificada e de consumo, pois não reconhece a sua potencialidade enquanto membro da coletividade e ator de ações individuais com efeitos positivos para o coletivo. Na sociedade massificada e de consumo, as ações com tendências individualistas, via de regra, não levam em consideração os impactos no coletivo social.

Pensando nas cidades contemporâneas pode-se notar como a forma de planejamento e desenvolvimento alterou-se rapidamente no decorrer do último século e com ela o modo dos indivíduos se relacionarem com o espaço. $\mathrm{O}$ contato com a natureza tornou-se restrito, assim como o compromisso ambiental. A natureza não se refere somente a um ambiente físico, de animais, plantas e minerais. A natureza não é um mundo "lá fora", não inventado por mentes humanas (HILLMAN, 1992). Um ambiente natural pode ser encontrado em meio a uma floresta ou em uma cidade. Estar em contato com a natureza é restaurar o sentido de maravilhamento às coisas simples do dia a dia. É compreender que um espaço cercado por construções humanas também compõe o que chamamos de natureza, portanto, necessita de cuidado.

Todavia, nossa percepção de natureza, assim como nosso laço com a mesma, encontra-se debilitado. Tuan (2012, p. 139), ao falar do modo como nos relacionamos com os espaços naturais, aponta 
Na vida moderna, o contato físico com o próprio meio ambiente natural é cada vez mais indireto e limitado a ocasiões especiais. [...] $\mathrm{O}$ que falta às pessoas nas sociedades avançadas (e os grupos hippies parecem procurar) é o envolvimento suave, inconsciente com o mundo físico, que prevaleceu no passado, quando o ritmo da vida era mais lento e do qual as crianças ainda desfrutavam.

Percebe-se que o ambiente físico e o estilo de vida atual, cada vez mais ligado as técnicas, afetam as atitudes e os valores ambientais, fazendo com que os laços com o meio natural se tornem cada vez mais limitados. A modernidade, como aponta Giddens (1991), altera a natureza da vida social cotidiana e afeta os aspectos mais pessoais de nossa existência. As instituições modernas se diferem das formas anteriores de ordem social e o grau de interferência nos hábitos e costumes tradicionais são expressivos, assim como o seu impacto global.

Essa ausência de compreensão da natureza traz uma série de consequências. Não se sentir parte integrante do meio ambiente é uma delas, o que desencadeia outras consequências, como o não engajamento com as causas ambientais e sustentáveis. Hoje, por passarmos tanto tempo envolvidos em um ambiente digital, acabamos por bloquear muitos sentidos humanos, inclusive alguns que nem sabemos que temos, tudo para podermos nos concentrar nas telas de computadores e celulares (MANSUR, 2016).

A ausência de contato com a natureza também traz consequências para o bemestar físico, emocional e social do ser humano. É na relação com o mundo que as múltiplas vias sensórias se manifestam, que as experiencias formadoras são registradas. Privar-se de experiências simples, como caminhar, encontrar pessoas, sentir-se ligado a natureza, rompe com possibilidades educadoras.

O pesquisador Ricahrd Louv (2016) em sua obra "A última criança na natureza: Resgatando nossas crianças do transtorno do déficit de natureza" descreve as consequências negativas à saúde quando experiências sensórias com o ambiente natural são negligenciadas. Dentre elas, o autor cita distúrbios de atenção, amortecimento de criatividade, obesidade e depressão, todos relacionados a uma infância deficiente de contato com a natureza.

É preciso restaurar os laços de ligação entre o homem e o meio no qual vive. Precisamos incorporar a educação da natureza e o conhecimento dos efeitos positivos em nossos hábitos diários, em nossas escolas, em nosso trabalho. Precisamos da natureza como antídoto para alguns dos efeitos negativos da tecnologia (MANSUR, 2016).

O ensino de geografia pode contribuir diretamente com este debate ambiental na medida que apresenta aos alunos o entendimento dos fenômenos socioambientais, numa perspectiva multifatorial, através da observação dos fenômenos físicos e da relação social do homem com os espaços. A Educação Ambiental, enquanto tema transversal, abre possibilidades para debates e posturas críticas frente aos problemas ambientais, assim como, estimula o contato com o ambiente natural. A mesma desponta como uma possibilidade de reencantamento, abrindo possibilidades de novos conhecimentos, metodologias e habilidades representando um instrumento essencial para a transformação do padrão existente de degradação socioambiental (SEGURA, 2011). A Semana do Meio Ambiente, apresentada no próximo item, é uma das formas de se trabalhar a Educação Ambiental, e a mesma tem sido um dos caminhos adotados por escolas para a discussão de temas relacionados a saúde do meio ambiente. 


\section{Dia Mundial do Meio Ambiente e seu potencial para o desenvolvimento de práticas ambientais sustentáveis}

Criado em 1972, na Assembleia Geral das Nações Unidas, o dia Mundial do Meio Ambiente, tradicionalmente celebrado no dia 5 do mês de junho, tem por objetivo estimular uma postura crítica e ativa em relação aos problemas ambientais existentes, bem como, ações cotidianas a fim de minimiza-los.

Frente a tamanhos e recorrentes desastres ambientais ocorridos no Brasil, bem como propostas de políticas de flexibilização de licenciamentos ambientais e uma deficitária fiscalização, o Dia Mundial do Meio Ambiente, longe de ser celebrado, deve ser uma oportunidade de reflexão e tomada de atitudes.

Diante de tais problemáticas ambientais, a educação ambiental (EA) se sobressai neste contexto estimulando uma integração social a fim de proporcionar mudanças na realidade e constituição da relação do homem com o meio ambiente (SILVA, 2007).

Em todos os âmbitos, do particular ao privado, do micro ao macro, a questão ambiental deve ser tomada como imprescindível e urgente. Para tanto é necessária uma prática contínua e responsável. Podemos salientar que a educação ambiental possui campo fértil para novas ideias, possibilitando sua inserção com eficácia nas instituições de ensino.

A educação ambiental formal não está inserida nas instituições como uma disciplina curricular específica, a mesma se insere por meio de uma concepção inter, multi e transdisciplinar, isto é, precisa ser abordada em todas as disciplinas do currículo de modo a correlaciona-la com os conteúdos específicos. A pretensão é que seja enfatizado a interdependência do campo social, cultural, econômico e da natureza, reforçando a reflexão de ações mais sustentáveis.

Os conteúdos em geografia muito se beneficiaram dessa perspectiva, pois se antes já arraigava para si o entendimento das problemáticas ambientais, com as diretrizes educacionais sobre a necessidade de inserção em todos os campos temáticos, ampliou-se o estimulo ao trabalho em conjunto dos profissionais da educação no trato da temática ambiental.

A realização da educação ambiental formal deve acontecer nas instituições públicas e privadas vinculadas as esferas municipais, estaduais e federais de ensino, seja na educação básica, educação especial, profissional, educação de jovens e adultos (EJA) e ensino superior.

O ambiente escolar é de extrema importância na realização da educação ambiental formal, se configurando como ambiente frutífero na troca de conhecimentos, estimulo a criatividade, socialização, entre outros aspectos que contribuem na construção desse saber.

Para prática do saber ambiental formal é indispensável enfatizar a necessidade de atividades de campo e de sala de aula, realizações de projetos que incentivem o comprometimento e responsabilidade com o meio ambiente e elevem a autoconfiança (Reis, Semêdo \& Gomes, 2012), sendo o lúdico o caminho que melhor sensibilizara a criança e o adolescente na jornada da aprendizagem.

Diante dessa perspectiva, muitas destas práticas ambientais tem sido estimuladas nas semanas destinadas ao meio ambiente, na qual estudantes, empresas, escolas, ongs, associações e prefeituras têm se reunido em torno da causa ambiental e proposto projetos que perdurem por longos períodos.

Eventualmente, nas semanas destinadas ao meio ambiente, são realizadas, em muitas cidades brasileiras o plantio de árvores e flores, mutirões de limpeza, feiras ambientais, ciclo de palestras e trilhas ecológicas. Tais ações, mesmo em escalas locais, 
são de grande importância, pois apresentam ações concretas que resultam em impactos imediatos e duradouros.

Como forma de ressaltar a importância da Semana do Meio Ambiente para a difusão do debate e de práticas ambientais sustentáveis, tomamos como exemplo o ciclo de oficinas realizadas no Colégio Estadual Manuel Bandeira, localizado na cidade de Cambé- PR. Em parceria com a Embrapa (Empresa Brasileira de Pesquisa Agropecuária), UEL (Universidade Estadual de Londrina), Cativa (Coperativa Agroindustrial de Londrina), Secretária do Meio Ambiente de Cambé e as universidades privadas UNOPAR e Pitágoras, foram realizadas oficinas produzindo debates produtivos que colocaram em pauta discussões acerca da crise ambiental e a urgência de práticas que revertam ou minimizem impactos que degradem o meio ambiente.

Nota-se o esforço do colégio em proporcionar espaços de debates e de proposição de projetos que impactem de maneira positiva a comunidade escolar, bem como, o seu entorno. $\mathrm{O}$ colégio em parceria com as entidades supracitadas, realizaram pequenas oficinas, buscando estimular a sensibilização ambiental e apresentar caminhos e ações para a efetivação de práticas ambientais sustentáveis e conscientes.

A atividade envolveu toda a comunidade escolar. Foram momentos de diálogos, trocas e união entre estudantes, docentes e palestrantes. Houve espaço para indagações, retiradas de dúvidas, proposições de ideias e atividades empíricas, proporcionando uma participação ativa às ações propostas.

A figura (1) ilustra o painel de entrada do Colégio Estadual Manuel Bandeira. Posicionado na entrada do colégio o painel teve como função demostrar que naquele ambiente havia um coletivo disposto a cuidar e debater a respeito das questões ambientais. O painel também questiona os alunos e a comunidade escolar, ao indagar a respeito do compromisso ambiental que muitas vezes não é assumido por todos.

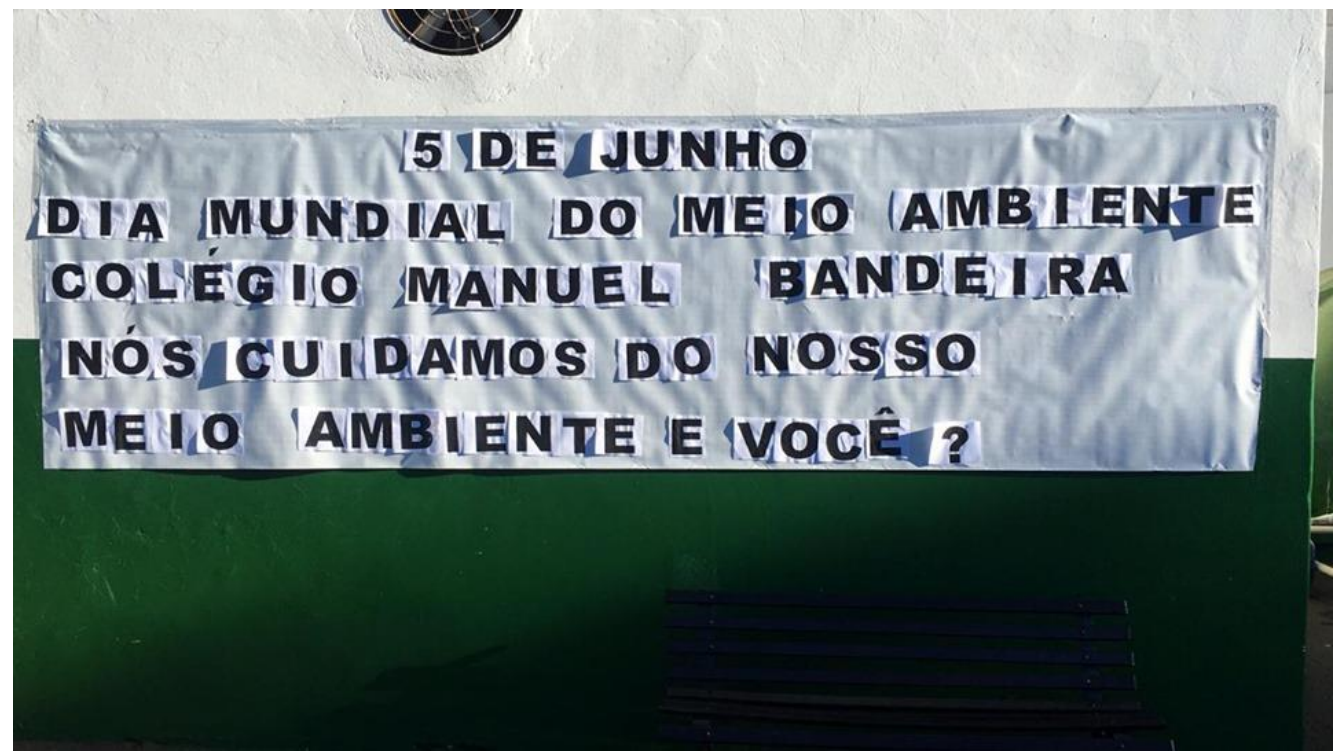

Figura 1: Painel de chegada do Colégio Estadual Manuel Bandeira - Cambé/PR Fonte: Arquivo pessoal do Colégio Estadual Manuel Bandeira - Cambé/PR.

A participação dos alunos nas oficinas foi parte fundamental nos debates das questões ambientais levantadas na Semana do Meio Ambiente. Através desses momentos os alunos tiveram a oportunidade de refletir sobre suas atitudes ambientais e de se perceberem como parte de um mundo complexo, que exige trabalho coletivo em prol da saúde e manutenção do meio ambiente. Tais momentos buscaram revelar que as ações individuais geram consequências para o coletivo, sejam elas positivas ou negativas. 
Um importante ponto de reflexão sobre a problemática ambiental, como método da educação ambiental, é a necessidade da incorporação de valores, habilidades e novas capacidades de delinear caminhos sustentáveis. De acordo com Leff (2009, p. 246), "a educação ambiental inscreve-se assim dentro de um processo estratégico que estimula a reconstrução coletiva e a reapropriação subjetiva do saber", em que se considera a aprendizagem um processo que parte das significações do aprendiz e conduz à mudanças na sua vivência.

A figura (2) representa uma das oficinas aplicadas durante a Semana do Meio Ambiente no Colégio Estadual Manuel Bandeira. O objetivo foi refletir sobre a quantidade de lixo que é produzido todos os dias e os prejuízos de não se adotar práticas que estimulem a reciclagem.

A prática dos alunos nas oficinas foi condicionada por um diálogo anterior, no qual se rememorou as problemáticas ambientais, e a partir de então, um debate sobre ações cotidianas que podem contribuir para o cuidado com o meio ambiente foi apresentado. Este diálogo anterior foi importante pois buscou contextualizar a importância da separação de resíduos, bem como, da reciclagem, ressaltando temas como o consumismo, o trabalho informal e o trabalho das cooperativas.

A reciclagem pode ser entendida como a separação sistemática de resíduos, sendo papéis, metais, plásticos, vidros, entre outros, destinados à mudança e reutilização na confecção de outros produtos. Dessa maneira, a reciclagem trata os resíduos como matéria-prima a ser reaproveitada para fabricação de novos produtos, concebendo um novo uso para resíduos que, até então, já não teriam mais utilidade.

Outro aspecto importante sobre a reciclagem é a geração de empregos e o impacto de trabalhos coletivos como o das cooperativas. Apesar de ainda não receberem de forma justa por tamanha contribuição social e ambiental, catadores de materiais expressam a necessidade de discussões acerca de profissões fundamentais a serem mais valorizadas, bem como, ressaltam a potência do trabalho coletivo, realizado pelas cooperativas, que contribuem com a saúde pública e o saneamento básico.

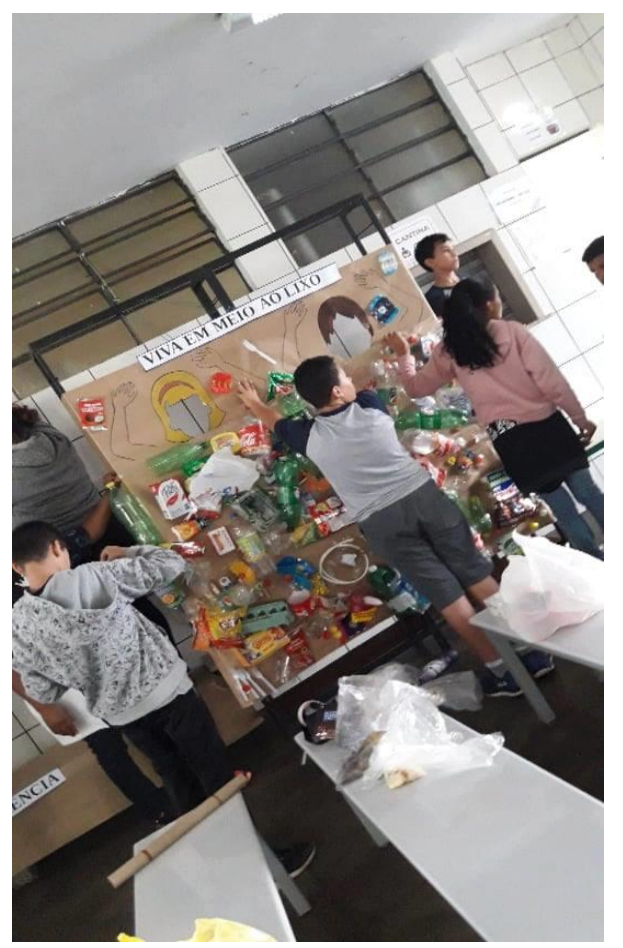

Figura 2: Participação dos alunos nas oficinas temáticas

Fonte: Arquivo pessoal do Colégio Estadual Manuel Bandeira - Cambé/PR 
Os resultados das oficinas, usualmente, são estimulantes para os alunos, pois há uma identificação com o trabalho final, aquilo que foi produzido em coletivo, será usado para o bem coletivo.

A compreensão de que os valores ambientais se delineiam desde a proteção dos ambientes gerais à uma ética política e social que englobe direitos coletivos e interesses sociais e ambientais (Leff, 2009) nos levam a refletir sobre os sujeitos que ao passarem a ter um contato com a Educação Ambiental, deterão possibilidades de transformar o futuro num local mais sustentável e democrático.

A figura (3) apresenta o resultado de uma das oficinas aplicadas, onde há a exposição dos elementos que contemplam a separação correta dos resíduos em seus respectivos cestos de lixo.

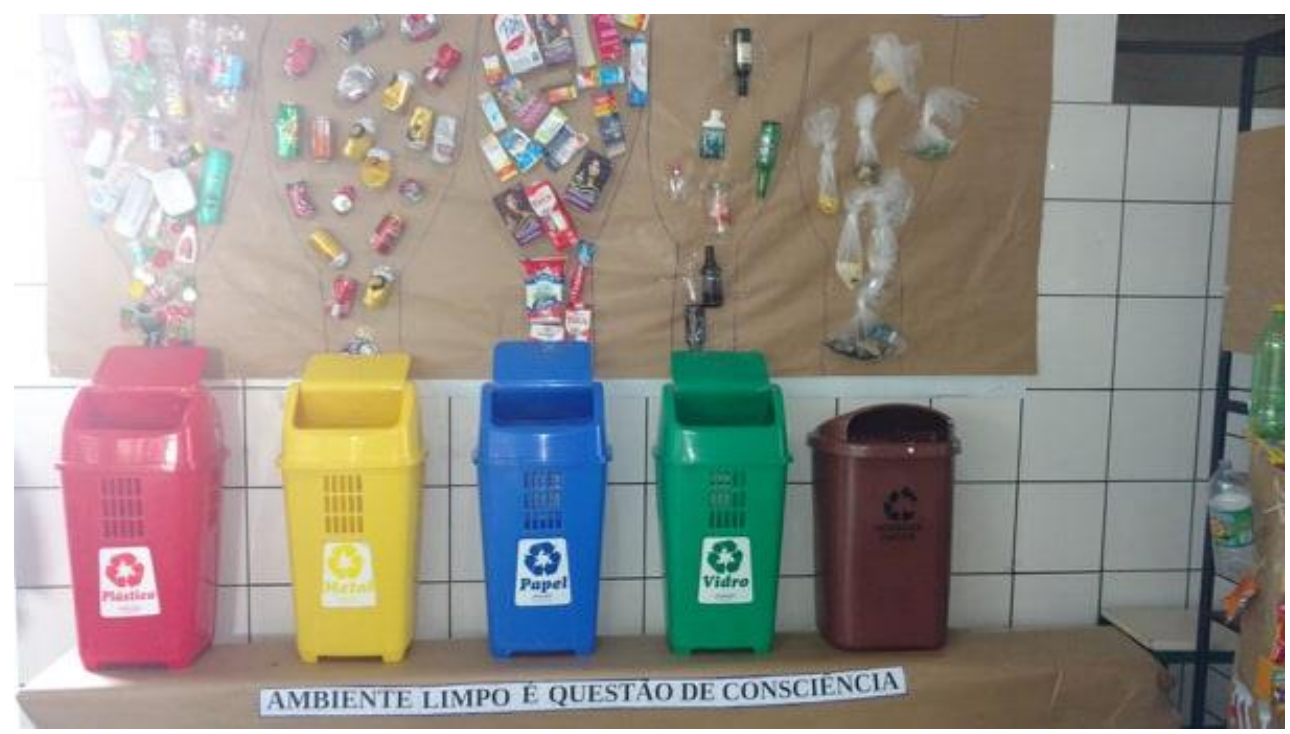

Figura 3: Resultado de oficina temática exposto para o colégio Fonte: Arquivo pessoal do Colégio Estadual Manuel Bandeira - Cambé/PR

As oficinas tendem, a depender da idade dos seus participantes, a gerar materiais mais lúdicos, com o objetivo de facilitar e assimilar a aprendizagem. O colégio se preocupou em desenvolver atividades neste sentido, contemplando as diferentes faixas etárias e sua metodologia de aprendizagem. As oficinas, de um modo geral, reforçaram como ações do cotidiano podem gerar bons resultados nas premissas de cuidado com o meio ambiente e com o mundo.

A proposta do colégio em aproveitar a Semana do Meio Ambiente para tais debates também reforçou como pequenas ações podem impulsionar boas práticas, extrapolando o ambiente escolar, e como a Educação Ambiental pode começar a ser introduzida na escola, todavia, sempre lembrando de sua ação contínua.

De um modo geral muitas práticas que poderiam ser realizadas com frequência, independente de datas, só são lembradas na Semana do Meio Ambiente, e no decorrer do ano permanecem esquecidas. Isso não se restringe as escolas, mas também as empresas e outras entidades.

Todavia, em meio a descompassos, não se pode negar a notoriedade desses eventos e as possibilidades que os mesmos oferecem na construção de projetos permanentes. Tal data ajuda na divulgação de projetos ambientais já existentes, assim como propaga e fornece visibilidade a pequenas ações, que lentamente, oferecem resultados e benefícios para o coletivo. 


\section{Considerações finais}

O ambiente escolar tem o potencial de sensibilizar os alunos, promovendo o despertar para uma relação harmônica entre homem-meio, demostrando que os "recursos" naturais não são inesgotáveis e que a degradação dos mesmos desencadeia não apenas a destruição da fauna e flora, mas afeta diretamente a sociedade, acentuando a desigualdade social na busca pelos meios de produção, bem como, a degradação do próprio espaço de vivência.

A geografa tem grande relevância nesse processo, podendo dar continuidade, através dos conteúdos escolares e das práticas transdisciplinares aos temas transversais, em especial a questão ambiental, tratada neste artigo. Por meio deste despertar sobre as questões ambientais, o ensino de geografia se fortifica e ganha relevância, revelando sua importância social ao educando, fazendo-o refletir sobre o consumo exacerbado, o reaproveitamento de materiais, a valorização do profissional da reciclagem, bem como, o papel da própria ciência na promoção de atitudes ambientalmente justas, assim como, o entendimento das relações socioambientais no contexto espaço-tempo.

Podemos mencionar, como contribuição da Semana do Meio Ambiente, a visibilidade de inúmeros projetos ambientais realizados em pequenas escalas, assim como a possibilidade de debates em torno da questão ambiental e o trabalho conjunto de profissionais das diferentes áreas do conhecimento, incluindo professores de geografia.

Nas oficinas ofertadas, vemos a importância desta data registrada na união de palestrantes, debatedores, instituições de ensino superior e alunos da educação básica. Tal proximidade proporciona uma troca de saberes, que extrapolam os saberes do currículo formal e reafirma que o cuidado com o meio ambiente permeia diversas esferas, ensino, pesquisa, extensão, órgãos públicos e privados, escola de nível básico e de nível superior.

Os conhecimentos que são propiciados nestas ocasiões vão além de assuntos sobre a lógica do sistema capitalista, que se atrela a produção em massa e ao consumo, gerando sérios impactos ambientais. Tais espaços revelam como todos podem contribuir para a manutenção de um meio ambiente equilibrado, partindo de pequenas (e necessárias) ações. As oficinas, neste sentido, estimulam ações que extrapolam os muros do colégio, pois o aluno uma vez motivado e certo de sua importância, leva consigo um conhecimento capaz de impactar as ações familiares, bem como, da comunidade ao seu entorno.

Vale ressaltar também que o debate sobre o consumo exacerbado, a destinação incorreta dos resíduos e a ausência de processos de reciclagem, entre outros assuntos que englobam as problemáticas ambientais, proporcionam aos alunos uma reflexão acerca do modelo industrial e, por vezes, social, que levam os sujeitos para caminhos da alienação e massificação.

As instituições de educação básica, por meio dos debates, oficinas e das ferramentas alternativas, acabam sendo mediadoras de um caminho para o pensamento crítico e capaz de abordar a realidade de forma a encorajar os alunos a promoverem ações mais sustentáveis e coletivas, tornando-se um espaço de múltiplas alternativas para o pensar e agir no mundo.

\section{Referências}

BAUMAN, Z. Vida Líquida. Trad. Carlos Alberto Medeiros. Rio de Janeiro: Jorge Zahar Ed., 2007.

CLAVAL, Paul. Terra dos homens. Editora Contexto, 2012.

DARDEL, E. O homem e a terra. Trad. Werther Holzer. São Paulo: Perspectiva, 2011. 
GIDDENS, Anthony. As conseqüências da modernidade. São Paulo: Editora Unesp, 1991.

HILlmaN, James. Cidade e Alma. Trad. Gustavo Barcelos e Lúcia Rosenberg, São Paulo. Ed. Studio Nobel, 1993.

LEFF, E. Saber ambiental: sustentabilidade, racionalidade, complexidade, poder. Trad. Lúcia Mathilde Endlich Orth. 7. ed. Petrópolis, RJ : Vozes, 2009.

LOUV, Richard. A última criança na natureza: resgatando nossas crianças do transtorno do déficit de natureza. São Paulo: Aquariana, 2016.

MANSUR, Alexandre. Estamos sofrendo o transtorno do déficit de natureza. Disponível : https://epoca.globo.com/colunas-e-blogs/blog-do-planeta/noticia/2016/06/estamos-sofrendo-o-transtornode-deficit-de-natureza.html. Acesso em 16 ago 2019.

SANTOS, M. Espaço do cidadão. 7. ed. São Paulo: Editora da Universidade de São Paulo, 2007.

SEGURA, Denise de Souza Baena. Educação ambiental na escola pública: da curiosidade ingênua à consciência crítica. Annablume, 2001.

SILVA, Viviane Aparecida. A relação entre educação ambiental formal e não-formal: um estudo de caso do Parque Natural Municipal de Taquara e as escolas do entorno. 80 p. Trabalho de Conclusão de Curso. Curso de Licenciatura em Geografia. Faculdade de Educação da Baixada Fluminense da Universidade do Estado do Rio de Janeiro, 2007.

TUAN, Y. Topofilia: um estudo da percepção, atitudes e valores do meio ambiente. (Tradução de Lívia de Oliveira). Londrina: Eduel, 2012. 